\title{
Shredding an EFL textbook: methodological implications in Secondary Education
}

DOI: $10.46932 / \operatorname{sfjdv2n2-030~}$

Received in: january 1st, 2020

Accepted in: March 30th, 2020

\author{
Sonia María Martínez Ponce \\ Máster profesorado. English teacher \\ Institution: RG Formación \\ Calle Rosalía de Castro, 44, 30107 Murcia
}

\begin{abstract}
The purpose of this paper is to show the qualities, methodology and characteristics of an EFL textbook. To do this, a detailed bibliographic review was carried out that served as the foundation to obtain the vision and background necessary to face, in the most objective way and with the broadest possible vision, the main objective - to show the qualities, methodology and characteristics of a EFL textbook- of research. The approach of the present work has been carried out in such a way that it can be easily understood not only by professors and researchers who are experts on the subject but also by the general population — due to the importance of the involvement of families in the teaching-learning process-
\end{abstract}

Keywords: Textbooks, Culture, EFL Teachers, Suitability of Teaching Material, Methodology

\section{INTRODUCTION}

Throughout this study I will critically analyse a current English Language Teaching (ELT) textbook, which will serve as a sample of an ELT book used in Spanish Secondary School nowadays. Thus, the textbook selected to be analysed is the following:

> Tune in (Student's book). By Michael Downie, David Gray and Juan Manuel Jiménez.

Santillana Educación S.L. / Richmond Publishing, 2008.

It should be taken into account that our legislation is explicitly based on the Common European Framework of Reference for Languages (CEFR) (2001). Therefore, according to this, our sample book is targeted at a low intermediate level (B1), being this stated on its own cover.

By the same token, it should be taken into consideration that complementary materials such as the corresponding Workbook, the Language Reference Book and the different CDs for independent study have been omitted from the analysis.

Additionally, it must be remembered that the current Spanish Organic Law of Education (Ley

Orgánica 2/2006, de 3 de mayo, de Educación), specifies in its objectives that students must "express themselves fluently and correctly in one or more foreign languages" (Art.33: f). 
The goal of this analysis is to answer the following question: Among a wide range of Foreign Language Teaching (FLT) methods, which one does this book follow? And why?

To successfully obtain the answers to these questions, I will carry out a series of procedures so as to reach an accurate conclusion. It is important to point out that the analysis will be carried out by exploring a single unit -out of nine- from the aforesaid textbook, which should provide enough evidence for the study of the methodology employed in the book as a whole. Thus, I will proceed as follows:

First of all, I will check up several activities proposed in that specific unit.

Secondly, I will classify these activities in different categories, depending on their purpose and structure.

Later, I will identify the ELT methodology in which they are included and, finally, I will justify my conclusion by giving supporting reasons aimed to describe the identified method.

\section{METHODOLOGY}

\subsection{MATERIAL DESCRIPTION}

Were the course book examined in more detail, a precise description of its structure should be provided. To start with, it can be seen that it is a topic-based textbook in which each unit deals with a different semantic field. More specifically, Tune In consists of nine units of study, each of them containing seven differentiated sections: "grammar", "vocabulary", "reading", "listening", "speaking", "writing" and "fine tuning". In addition, after each three units, there is a review section that provides quick tests for students to check whether they have acquired the proposed knowledge or not. At the end of the book, communication activities, a language reference per unit, the audio scripts of the listening texts, some grammar charts and some extra information files give access to additional practice.

Each unit contains a heading which expresses a general concept or idea, closely related to real life. They are as follows:

Unit 1: Travel the world

Unit 2: Lucky escapes

Unit 3: Alternatives

Unit 4: Detecting crimes

Unit 5: Advertising
Unit 6: A place to live

Unit 7: Stars in their eyes

Unit 8: Working it out

Unit 9: Exam success 
Table 1. Contents of the unit selected from Tune In

\section{UNIT 5: ADVERTISING}

GRAMMAR: Passives; Omitting the agent; Direct and indirect objects; Impersonal passive structures VOCABULARY: Homonyms and homophones / Advertising collocations.

READING: The beautiful message. Tune in to Reading: Avoiding repetition.

LISTENING: Advertising slogans. Tune in to Listening: Choosing between similar answers.

SPEAKING: Interaction: Debating an issue. Tune in to Speaking: Interrupting politely.

Production: Talking about an advertisement.

WRITING: A formal letter. Tune in to Writing: Formal English.

FINE TUNING: Phrasal verbs: money; have/get something done; binomials; formal and informal letters.

I have highlighted the four language skills -reading, listening, speaking and writing- intending to underline the meaning of their appearance all over the book. It is important to point out that they are presented as very important parts of the teaching-learning method, even more when all of them seem to hold the same importance at first sight. The rest of sections appear inside coloured charts which are inserted in the different spaces reserved for the skills sections. Thus, "Vocabulary" section is contained both within the "Reading" part - providing examples of homonyms and homophones- and the "Speakinge one - advertising collocations-, while the "Grammar" section appears in the pages dedicated to "Listeninge tasks. Furthermore, we can also find little charts in each section containing advices or extra information about a specific topic; these are the "Tune in to Reading / Listening / Speaking / Writinge charts. Regarding the "Fine Tuning" section, it is arranged at the end of each section of language skills, arising different questions each time and providing help for each of them at the end of the book, so the students must be asked to move there in order to work on it.

Additionally, it should be taken into account that what has been analysed is the set of activities

(their goals and strategies) offered by the textbook, but not the teacher's implementation of the activities in real classrooms.

Having thus established the basis for the analysis, and without further ado, we can start working on it. 


\section{ANALYSIS}

The activities proposed in the section dealing with "reading skills" are based on an article about the negative messages and images that may be transmitted by advertisements; more specifically, dealing with the issue of "thinness" as an outcome of injurious advertising. Therefore, these are textbased activities, in which the text, under the headline "The beautiful message", can actually be used as a stimulus for the tasks given. Learners must understand the content of the text as a whole in order to get the main idea and be able to fill in the information gap they have. These activities are intended to make the reader work on the text by employing the techniques of skimming and scanning, amongst others. Thus, in activity number 1 (page 38 ) the student is asked to read only the title of the article and, from then on, he must answer the questions provided, which enhance him to be creative and thoughtful about the message transmitted by the title without further information. Then, in activity 2 , the student will have to skim the article to check their answers; this is, to look only for the general or main ideas of the text. On the other hand, in activity 3, the student will need to scan the article in order to look for a specific fact (numbers references in this case) without reading everything. Nevertheless, activities 4 , 5, 6 and 7 are meant to make the student read carefully and deeply the whole text, in order to either choose the true sentences, find synonyms used in the text for the words provided, or answer questions about his/her personal opinion regarding important issues that have been treated in the text.

Additionally, activity 7 challenges the student with a Problem-solving task about the key idea of the text, and thus the student has to show his ability to critically analyse a problem.

In the "listeningee section we can only find a "recordingee activity, which acts as the basis for the whole section; it is activity 3 from page 40. Before the activities, there appears the "Tune in to Listening" chart, which deals in this case with advices about how to choose between similar answers, providing thus help for the execution of the activities which will follow.

Activity 2 provides the sentences about the topic of the future recording ("Coca-cola"). These five sentences are incomplete, so there are three different statements for each of them. Up to this point, the student is only asked to read the questions and differentiate between the options. It is in activity 3 where the student is said to listen and to choose the statement -only one for each-, which will make the complete sentence true -according to the information given by the recording.

The teaching purpose here is to ensure the understanding of the written pre-information given (task 2) so as to better understand the aural information that is to come (task 3), and thus achieving the goal successfully by implementing both tasks. 
Apart from this we can find other activities within the "grammar"e chart such as drills, question-and-answer exercises, rewritings, matching concepts, etc., basically intended to put into practice the different use of passives.

In the "speaking: interaction" section, activity 2 (page 42) is a "recording" activity -again-, and activities 3 and 4 are also related to it; activity 3 promoting the fine listening of the recording in order to identify everyday expressions. In the "speaking: production" section (page 43), we find another "recording" activity (activity number 2) and other activities to work on this recording; at the end, in the little section "On Air", the student is asked to communicate with their colleagues by describing an advert and thus practising the "speaking" skill.

Finally, in the "writing" section, activities are aimed to provide the student with information about how to produce a formal letter, by using different strategies. In activity 9 (page 45) the student is finally asked to put into practice the former advices -and some else concepts to help- by writing a letter of complaint.

As I have mentioned before, we also find exercises towards the end of each section aimed to make the student practice vocabulary and grammar by filling in the gaps (except for the "writing" section). For instance, in activity 5 from the "vocabulary" chart in the "reading" section (page 39), there are homonyms for the student to choose where they better fit in, while in activity 4 from

"Speaking: Production" (page 43), the words to choose in the box are different verbal tenses.

And we can also find in activity 5 from the "Grammar" section (page 41), a cloze test with verbal forms in the passive tense in order to practice them in a given context.

Throughout the whole unit, communication is promoted by encouraging pair-and-group work learning among students. We can find several group activities: activity 7 (page 39), activity 5 (page 42) and 4 ("vocabulary" section), and activity 1 (page 43).

In addition, activity 5 from the "speaking: interaction" section (page 42), offers a simulation, making the students play different roles and employing them to opine about an imaginary situation. This way the group of students interacts to negotiate meaning through the practice of the four skills.

It is important to point out, as this is the Student's book, that we cannot know exactly what the teacher should do. Nevertheless, it is clear that students are responsible of their own learning as the main communicators, while the teacher is just an organizer or facilitator.

Another important matter is that there is no evident use of the native language or L1 (Spanish), but students are encouraged to use the foreign language or L2 (English) in each activity. 
Also, there is a great use of realia or authentic materials, both language-based realia -as in the case of the advertisements, articles and real photographs provided-, and also graphic and visual sources for the construction of activities, such as colourful charts and pictures.

Moreover, and considering the majority of the activities of this lesson, we should close this section by saying that there is a wide variety of them highlighting content over form.

\section{IDENTIFICATION}

Taking into account the group of data formerly compiled, I will now proceed to identify the method that fits best to the description and analysis of the elements provided above.

In my opinion, it seems to indicate that the selected textbook, Tune In, is framed by the Communicative Language Teaching (CLT) method.

According to Sánchez (1993: 83), "the features that define a communicative process must be the ones of a communicative activity". Thus, he explains the identifying characteristics of communicative activities, which are going tobe summarized below.

First of all, these activities try to achieve the transmission of some information (meaning) between both interlocutors, who are interested and motivated to do it. Also, the activity has a final goal or purpose, which has to be mainly communicative as well as it is focused on the content and not in the form through which the information is exchanged. Besides, the four skills can be used to develop the activity and the formal elements followed to learn should be there, but merely as a means and not as a goal. Apart from that, a code must be shared among the interlocutors and the interactive activity should take place in a context where authentic materials will favor to create real communicative challenges (Sánchez, 1993).

In this section, I have employed my own principles by adapting Sánchez's (mainly 1993, but also 1997, 2004 and 2009) "whys", "hows" and "whats" of CLT and his description of the communicative activities. In order to do so, I have created some parameters to prove if the different activities from the analyzed unit convey the main features of the CLT, which are as follows:

1. Encourage learners to speak in the L2 limiting the use of L1.

2. Transmit a message between the interlocutors in order to fill an information gap that existed between them. 3. Be involved in a real communicative situation where language is contextualized. 
4. Create a simulated situation of the real life of the students where they can do something/ are encouraged to get a communicative goal.

5. Develop the use of any of the four skills; either receptive (reading and listening) or productive skills (writing and speaking). 6. Encourage interaction between students promoting communication.

7. Focus on practicing some communicative functions by promoting the learner's use of the target language instead of teaching formal linguistic elements (grammar/ vocabulary/ pronunciation).

8. Motivate and interest students encouraging them to work.

9. Use authentic materials and real objects -realia- like for instance, newspapers, advertisements, graphics or any kind of visual sources to motivate and facilitate the consolidation of new vocabulary.

10. Practice the previous grammatical explanation indirectly by leading the use of language and improving the communicative ability.

11. Avoid mechanical repetition of patterns and structures where grammar is used explicitly as the focal point. 12. Favour the establishment of a natural and real communicative situation.

13. Give importance to the content (what) learners are transmitting and not just to the form (how). 14. Be framed within a specific topic or semantic field.

15. Favour the active participation of the student as the main character of the process.

Without further ado, and since the majority of the analyzed activities convey most of these features, I can safely say that the method employed in the production of this EFL textbook has been the Communicative Language Teaching approach. 


\section{RESULTS AND DISCUSSION}

Due to the fact that the presence of communicative features is higher than those of the absence, we have proved that this textbook achieves a high degree in its communicative nature. In my opinion, analyzing a book in detail is the best option to ascertain up to what point it complies with the principles of the method prescribed and therefore, whether it is going to be useful in an ELT classroom. 


\section{REFERENCES}

Al Harbi, A. A. M. (2017). Evaluation Study for Secondary Stage EFL Textbook: EFL Teachers' Perspectives. English Language Teaching, 10(3), 26-39.

Ali, M. (2014). AN EVALUATION OF'ENGLISH FOR TODAY: FOR CLASSES 11-12'AS A TEXTBOOK FOR BANGLADESH HIGHER SECONDARY EDUCATION (HSE). English Teacher, 43(1).

Alonso, J. M. R., López, M. E. M., \& Abellán, A. L. (2020). Didáctica a través de las emociones. Validación cuestionario percepción emocional del profesorado (PEP). Brazilian Journal of Development, 6(11), 91962-91979.

Alonso, J. M. R., Rosique, R. C., Pérez, R. S., Robles, C. M. S., \& Romero, M. G. (2020). Didáctica a través del cuento. Validación cupic. Brazilian Journal of Development, 6(12), 95146-95159.

Galian, A. L., Nicolás, Á. G., \& Alonso, J. M. R. (2021). School organization and confinement. Didactic focused on reducing the impact of covid. Peiwecs. South Florida Journal of Development, 2(1), 383-394.

García, S. G., Nicolás, A. H., Cano, M. G., \& Alonso, J. M. R. (2021). Giftedness in the students of the second cycle of childhood education. Intervention strategies in the classroom. South Florida Journal of Development, 2(1), 164-175.

González, M. G., \& Alonso, J. M. R. (2021). ICT in Primary Education. Review of its importance and a proposal. South Florida Journal of Development, 2(1), 131-144.

López-Alonso, J. M., Grumel, E., Cap, N. L., Trivi, M., Rabal, H., \& Alda, J. (2015, September). Characterization of dynamic speckle sequences using principal component analysis and image descriptors. In Optics and Photonics for Information Processing IX (Vol. 9598, p. 95980Q). International Society for Optics and Photonics.

Muñoz, J. G., Calderón, B. C., Melgar, R. M., \& Alonso, J. M. R. (2021). Importance of the use of interactive methodologies in primary education: gamification. Didactic proposal. South Florida Journal of Development, 2(1), 264-274.

Romero, M. G., \& Alonso, J. M. R. (2018). Aportaciones docentes sobre la programación docente en la etapa de Educación Infantil. In IV Congreso Virtual Internacional sobre Innovación Pedagógica y Praxis Educativa INNOVAGOGÍA 2018: libro de actas: 20, 21 y 22 de marzo 2018 (p. 43). AFOE. Asociación para la Formación, el Ocio y el Empleo.

Velázquez, A. B. G., Marín, P. O., López, Y. M., \& Alonso, J. M. R. (2021). Acercamiento a la atención a la diversidad desde la perspectiva de los profesionales de educación. Brazilian Journal of Development, 7(3), 20999-21014. 


\section{APPENDICES}

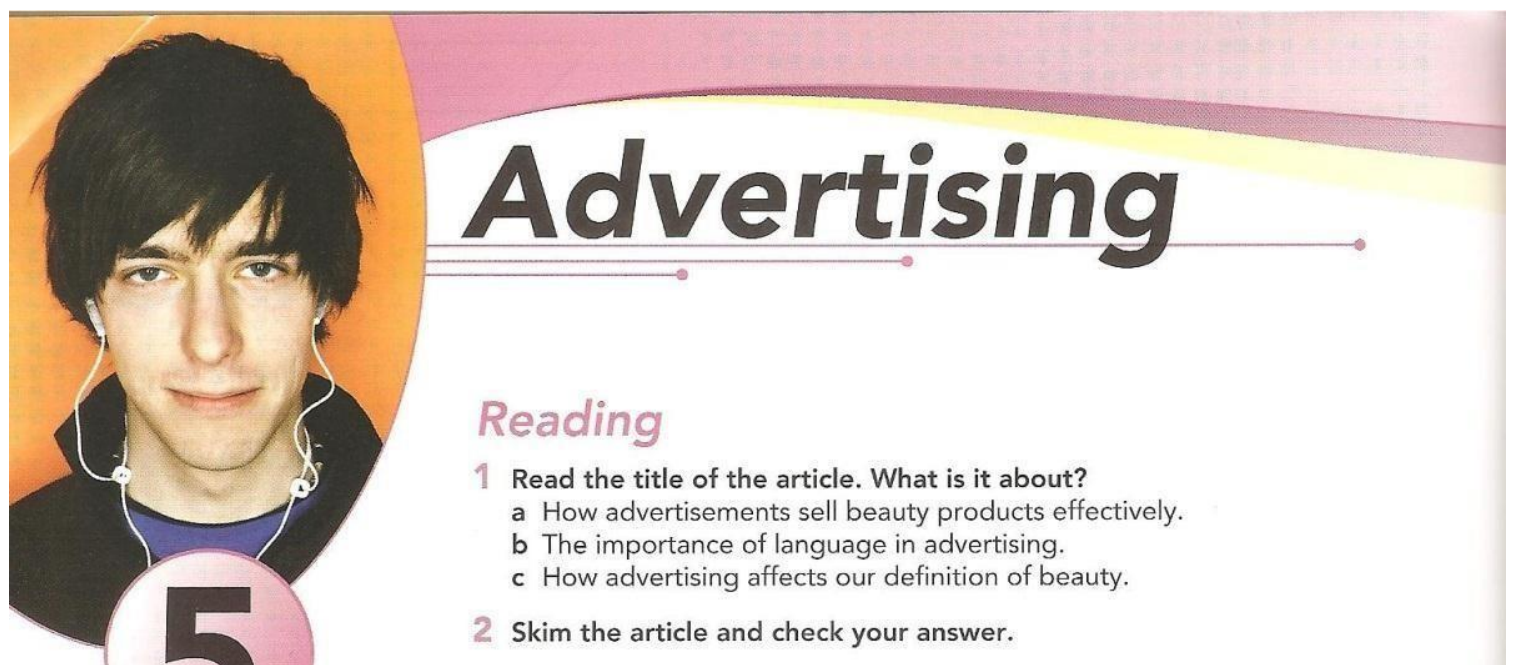

2 Skim the article and check your answer.
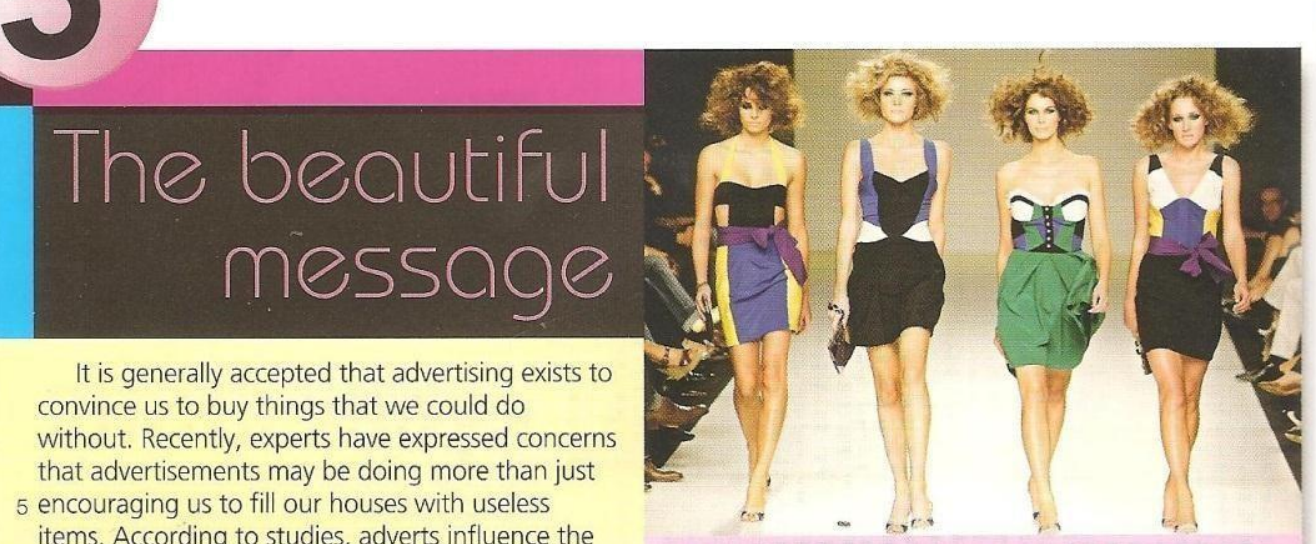

ideas of the perfect body shape. Another investigation, which was carried out by Stanford consequences. It seems that young women, and increasingly young men, are particularly vulnerable

10 to the messages and images transmitted by advertisers.

Research suggests that by the time a girl is seventeen years old, she has received over 250,000 commercial messages. The majority of these use

15 beauty to sell products and this is what affects teenagers' perceptions of their own bodies. Thinness, in particular, is promoted as a standard for female beauty with many commercials idealising bodies which are atypical for normal, healthy women. The

20 reality is that top models weigh approximately $23 \%$ less than the average female. A modern young woman, between the ages of eighteen and thirtyfour, has only a $1 \%$ chance of being as slim as a supermodel.

25 Sadly, many teenage women believe what they see in TV adverts or on billboards. Over $60 \%$ of girls in one study said that fashion models influence their

30 University, found that $68 \%$ of the respondents felt worse about their own appearance after flicking through women's magazines. As a result of this dissatisfaction, many young women and girls desperately want to lose weight. Some reports

35 suggest that being thinner is the number one wish for girls aged between eleven and seventeen. It appears that even children as young as five years old express fears of being fat. The danger is that adolescents follow drastic diets and adopt unhealthy

40 weight-control habits in an attempt to emulate fashion idols.

The message to transmit to teens is that advertising is not concerned with promoting reality, but products. The glittering world of beautiful, thin 45 people simply does not exist. It might help to remember the proverb, all that glistens is not gold, the next time you feel persuaded to buy something by an advert.

3 What do these numbers in the text refer to? 1250,000

223

31

460

568

4 Identify the true sentence in each group. Find evidence in the text to support your answers. 1 a The majority of advertisements convince us to buy things for our houses.

b The majority of adverts convince us to buy beauty products.

c Advertising convinces us to buy things we don't really need. 


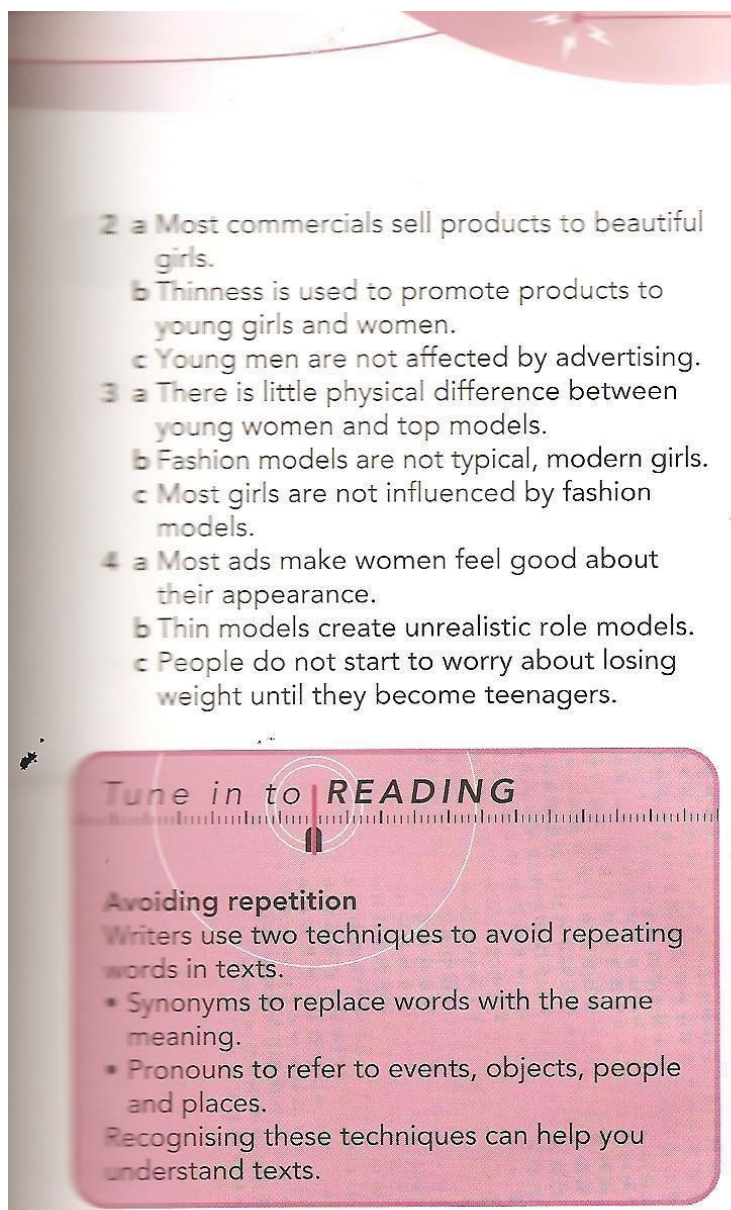

5 Read the text again. What synonyms does the writer use for these words?

1 advertisements

2 studies

3 young women

4 lose weight

5 drastic diets

6 Find these pronouns in the text. What do they refer to?

1 she (line 13)

2 these (line 14)

3 this (line 15)

4 they (line 25)

5 their (line 27)

7 Work in groups. Ask and answer the questions.

- Do you agree with the article?

- Do fashion models influence the way

we see ourselves?

- Should very thin models be used

in advertising?

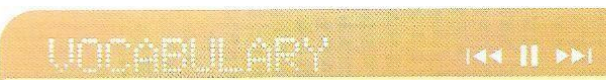 \\ Homonyms and homophones \\ 1 Look at the words in bold. What do they mean? \\ 1 My favourite flower is the rose. \\ 2 Bread is made with flour and yeast. \\ 3 If you meet the queen, you have to bow. \\ 4 The little girl had a pink bow in her hair.}

2 How are the words in exercise 1 pronounced and spelt?

3 What do we call words with the same pronunciation or spelling, but different meanings?

4 Identify the homonyms and homophones in these sentences.

1 Can you draw this for me? I'm terrible at art.

2 The football match ended in a draw.

3 I'm going to ring John and see if he's free tonight.

4 I lost my wedding ring at the swimming pool.

5 I think the boss will fire Paul: she is really angry!

6 There was a bad fire in the forest last year.

7 Adverts can affect us in negative ways.

8 Have you read the label on that can of food?

9 Do you know my friend John?

10 No, I don't. I have never met him.

11 I weigh myself occasionally.

12 The best way to look good is to feel good!

5 Complete the sentences with the homonyms in the box.

bright general lie patient rock well $1 \mathrm{~A}$ _ provides drinking water for the village.

2 A directs an army.

3 Do you like __ music?

4 She is a very ___ student - she always gets top marks.

5 A nurse looks after a ___ in a hospital.

6 Don't __ _ honesty is the best policy!

6 Write another sentence for each homonym in exercise 5. 


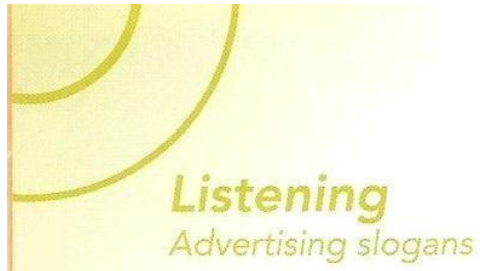

1 What slogans are used to advertise this product?

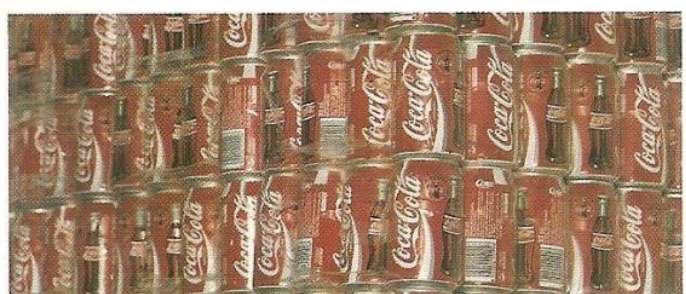

\section{Tune in to LISTENING (1)}

Choosing between similar answers

To choose between multiple choice answers.

- Read the questions carefully.

- Use your knowledge of the topic to select

the correct option.

- Use your knowledge of English to differentiate between the options. Consider grammar, vocabulary and pronunciation.

- Listen and choose the correct option.

Read the questions and differentiate between the options.

1 Coca-Cola was invented by...

a Doctor Julia Pemberton.

b Doctor John Pemberton.

c Doctor John Pharmacist.

2 Coca-Cola is consumed by over..

a one million people a day.

b one billion people a year.

c one billion people a day.

3 Coke first sponsored a TV programme...

a in 1850.

b in 1955.

c in 1950.

4 There was a period of political uncertainty...

$a$ in the seventies.

$\mathrm{b}$ in the $17^{\text {th }}$ century.

$c$ in the eighties.

5 A new Coca-Cola was introduced in the...

a early eighties.

b mid-eighties.

c late eighties.

3 15.10 Listen and choose the correct options.

4 Order the slogans. Listen again to check.

1 Have a Coke and a Smile

2 Look Up, America

3 Be Really Refreshed

4 Coke Is It!

5 Things Go Better with Coke

6 Coke Adds Life

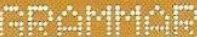

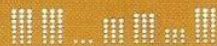

\section{Passives}

1 Read the examples and complete the rule.

1 Coca-Cola is consumed by a billion people a day.

2 Coca-Cola was first sold in 1886.

3 Television advertising was being used throughout the 1960s.

4 Young consumers could be targeted using popular musicians.

We form the passive with the appropriate form of the verb + the participle.

2 When do we use the passive?

a when we are more interested in the action

b when we are more interested in who or what performs the action

3 Rewrite the sentences in the passive.

1 Advertising agencies are planning hundreds of campaigns right now.

2 Large corporations hire young sports stars like Rafael Nadal.

3 Several big brands dropped the model Kate Moss in 2005.

4 Some unscrupulous model agencies have exploited young girls.

5 Staff were discussing the new advertising campaign when the director arrived.

6 The director had already taken the decision before the meeting.

7 The internet will change the future of advertising.

8 In the future, consumers are going to buy more products over the internet.

9 This may force some companies to close down.

\section{Omitting the agent}

1 Look at the examples. Do the words by someone add information?

1 My camera was stolen yesterday.

2 My camera was stolen by someone yesterday.

2 Rewrite the sentences in the passive. Can you omit the agent?

1 Workers in Japan made my camera.

2 They are going to sign a new agreement tomorrow.

3 Publishers publish hundreds of self-help books every year. 


\section{Direct and indirect objects}

1 Look at the examples and answer the questions.

1 Advertisers pay models a lot of money.

2 Models are paid a lot of money by advertisers.

3 A lot of money is paid to models by advertisers.

a How many objects does the first sentence have?

b Which is the direct object? Which is the indirect object?

c What differences can you find between examples 2 and 3 ?

2 Write two passive sentences for each of these sentences.

1 Adverts promise girls a happier life.

2 They sold the new product to Gavin.

3 They sent him a free bottle of aftershave.

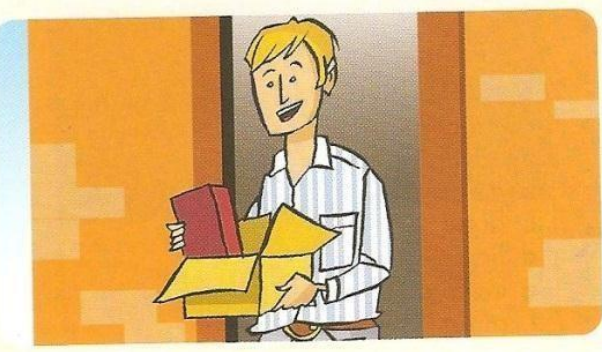

Impersonal passive structures

1 Match the sentence halves to make new examples with a similar meaning.

People say that Coca-Cola represents the American way of life.

1 It is said that Coca-Cola..

2 Coca-Cola is said...

a to represent the American way of life.

$b$ represents the American way of life.

2 Rewrite the sentences using the prompts.

1 Experts estimate that billions of pounds are spent on advertising each year. It...

2 The specialist press reports that car companies spend the most money. Car companies...

3 People think that Asian economies wil attract most investment in the future. It...
3 Look at the examples. How does the reporting structure change in the past? 1 The Coca-Cola company is said to make huge profits every year.

2 The company is said to have been especially profitable last year.

4 Rewrite the sentences using the prompts.

1 People say that the managing director was fired last night.

The managing director...

2 Everyone knows that the owners were not very happy with him.

The owners...

3 Employees think that he was on the point of announcing his resignation. He...

4 Experts consider that his job was extremely difficult. His job...

5 Complete the text with these words. he was being offered was assigned will be opened was given was recruited was known to be will be offered He was told it was suggested to John

Many young people dream of working in dvertising agency. They think they an advertising agency. professional success ${ }^{2}$ __ to them. But it doesn't always happen that way. John ' New York agency three years 3 _ by a New York a ago. ${ }^{4}$ that he would be working with important clients. But John ${ }^{5} \_$very boring jobs at first. After two months of making coffee and doing photocopies, 6 that he might like to join the director's staff. He was delighted - until he discovered that 7 a job as the director's driver! Not only that, but the director 8 a very hard worker, so dir have to work very late. Three John would have to worim by

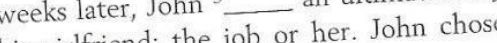
his girlfriend: the job or he her and resigned the next day.

FINE TUNING Can you form passives with have/get + past participle? $\Rightarrow$ Turn to page 94 


\section{Speaking: Interaction}

Debating an issue

1 Look at the advert. Who is it aimed at?

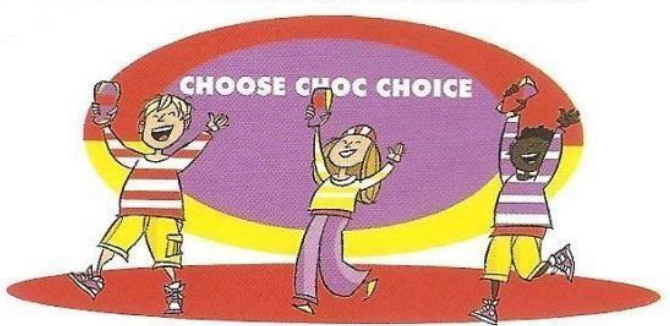

2 (5.2) Listen. Do the speakers like the advert? Why? Why not?

\section{Tune in to SPEAKING (I)}

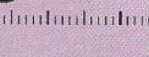

Interrupting politely

To interrupt a person when they are speaking, we can use expressions like Hold on a minute or Wait a minute. The person speaking can either accept the interruption or reject it.

3 Listen again. Which of these expressions do you hear?
a Hold on a minute.
$f$ Wait a minute.
b Yes?
g Oh, come on!
c What are you saying?
h Julie, just listen a
d Hang on there.
minute.
e Let me finish.
i OK, sorry.
j What?

4 Match the expressions from the tapescripts with the categories.

1 interrupting

2 accepting an interruption

3 refusing an interruption

5 Work in groups of three. Discuss the topic. Underweight models should be banned from advertising

Student A: You work for an advertising agency

Student B: You are a parent

Student C: You are a politician

\section{ON AIR Can you debate an issue?}

Choose one of the issues and discuss it in groups.

- Advertising on television

- Celebrity endorsement of products

2 For help with debating an issue, turn to page 112.
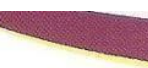

(n)

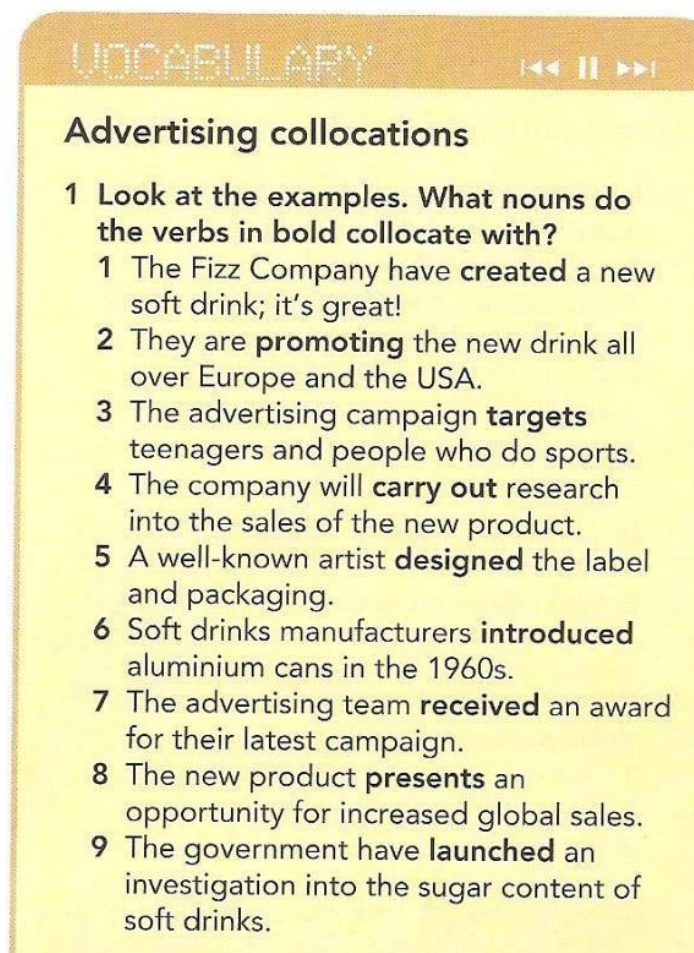

2 Match the verbs in exercise 1 with the definitions.
a advertising
b do
c drew
d first sold
e invented
$f$ offers
$\mathrm{g}$ is aimed at
h started
i were given

3 Find other words in the unit that collocate with the verbs.
1 create
2 promote
3 target
4 carry out
5 design
6 introduce
7 receive
8 present
9 launch

4 Work in groups and play the minute game.

- Take turns to talk about advertising for one minute.

- Get one point for every correct collocation you use.

- Get five extra points if you talk for a complete minute. 


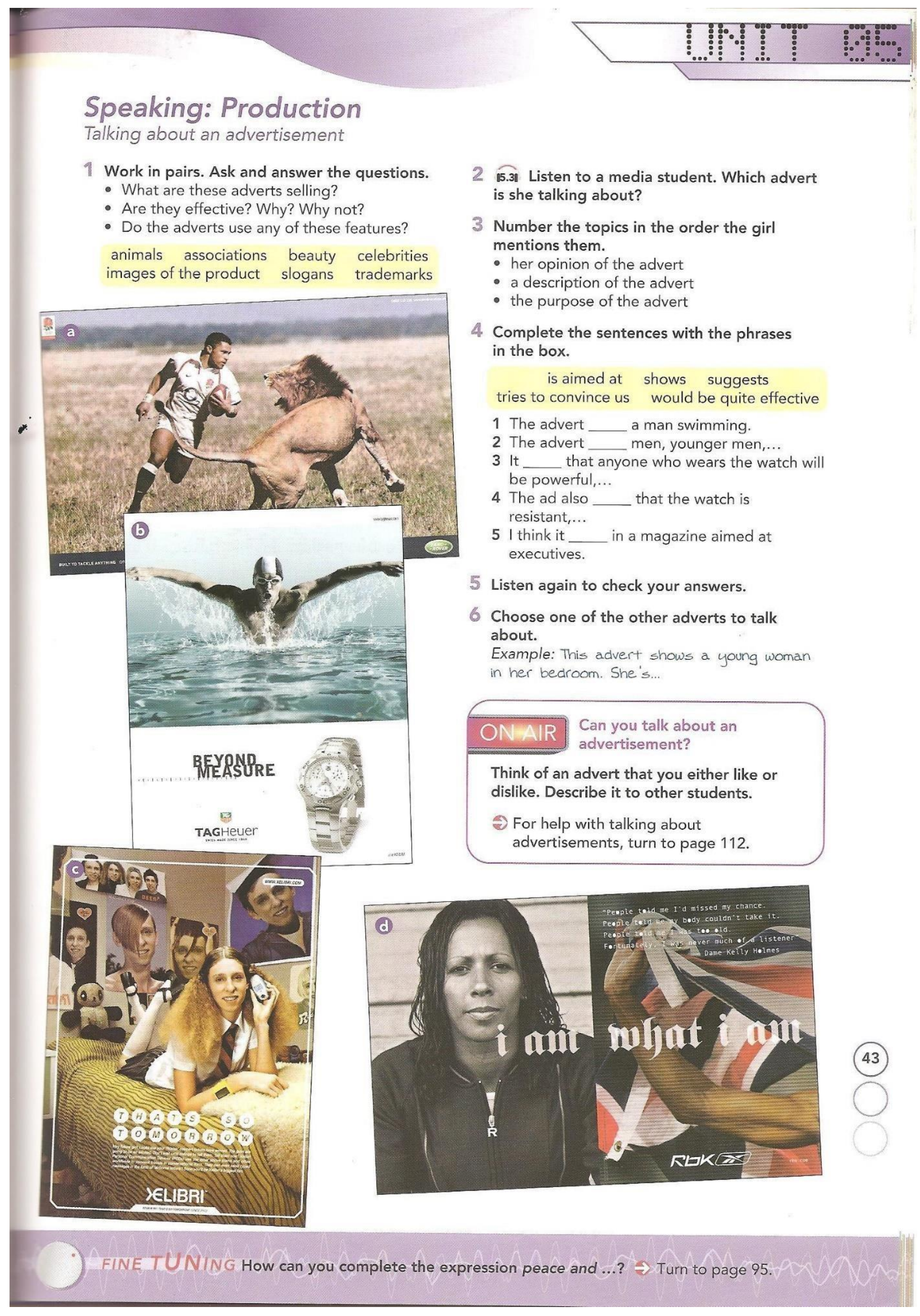



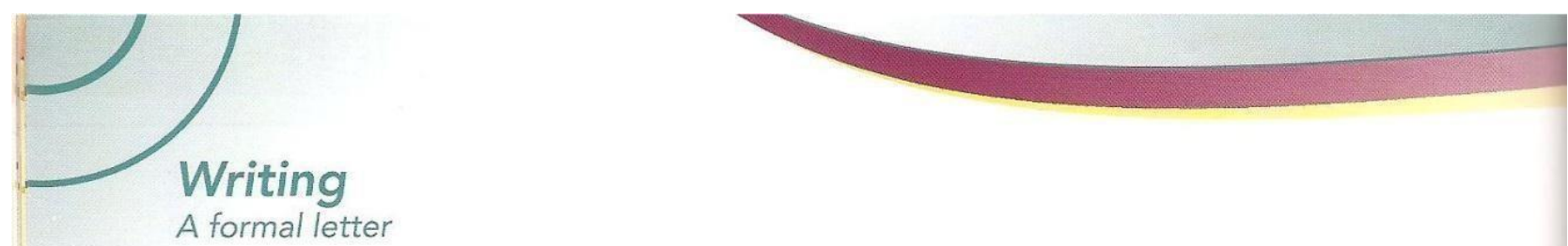

A formal letter

1 Read the advertisement and answer the questions.

1 What is the advert for?

2 What positive features are mentioned?

3 Would you like to spend a holiday there?

For a Weelrend you
Will never forget,
come to the

2 Read the letter and answer the questions.

1 Who wrote the letter?

2 Who is the person writing to?

3 Why is the person writing the letter?

3 What do the words in bold refer to?

1 It (paragraph a)

2 these (paragraph b)

3 they (paragraph b)

4 This (paragraph b)

5 it (paragraph c)

6 these (paragraph c)

4. Match the paragraphs of the letter with the descriptions.

1 further information

2 the details of the complaint

3 the reason for writing

4 the writer's closing

\section{Tune in to WRITING} .

Formal English

Writers use the passive voice and more formal vocabulary when they write formal texts like a letter of complaint.

5 Find examples of the following in the letter. 1 the passive voice

2 formal vocabulary
14 Chestnut Avenue Walstin-on-Thames

13 April 2008

The Manager

Seaview Hotel

14 Beachfront Street

Norton-on-Sea

Dear Sir or Madam,

I am writing to complain about my weekend stay in your hotel. It was, as your advert stated, a weekend I will never forget. I would like to request a full refund of my bill.

(b) I was promised a relaxing weekend in beautiful rooms with wonderful views. From my bedroom window, I could only see the busy main road and the hotel car park. Neither of these was relaxing, especially late at night. My individual bathroom facilities were, in fact, a hand basin in the corner of the room, and a shared bathroom along the corridor. When the staff were informed of these problems, they expressed no interest and did nothing to make my stay more pleasant. Finally, I found that the hotel was actually a fifteen-minute walk from the beach. This was particularly disappointing.

C I will not be visiting your hotel again. What is more, I will not be recommending it to my friends or colleagues. I have also written to the editor of the newspaper where you advertise to point out the inaccuracies in your advert. I trust these will be rectified as soon as possible.

d I look forward to hearing from you regarding my complaint and to receiving a full refund.

Yours faithfully,

Nigel Dawson

Nigel Dawson 
6 Match the sentences with the more formal equivalents.
1 We talked about what was wrong.
2 I won't be recommending your hotel.
a I will not be recommending your hotel.
3 The staff couldn't have cared less.
b Nothing was done to resolve the situation.
4 Nobody did anything to sort out the mess.
5 The advertisement told a lot of lies.
c The advertisement was very misleading.
d The staff were not at all concerned.
e We discussed the problem.

7 Rewrite the sentences in a more formal way using the prompts.

1 Nobody cleaned my room.

My room...

2 I didn't have a good time.

I...

3 The staff ignored my comments.

My comments...

4 I'm just dropping you this note to complain about your hotel. I...

5 We couldn't eat the food in the restaurant: it was so bad.

The... inedible.

6 I won't be telling my mates to come to your hotel.

I...

8 Read the advertisement. Would you like to spend a weekend there?

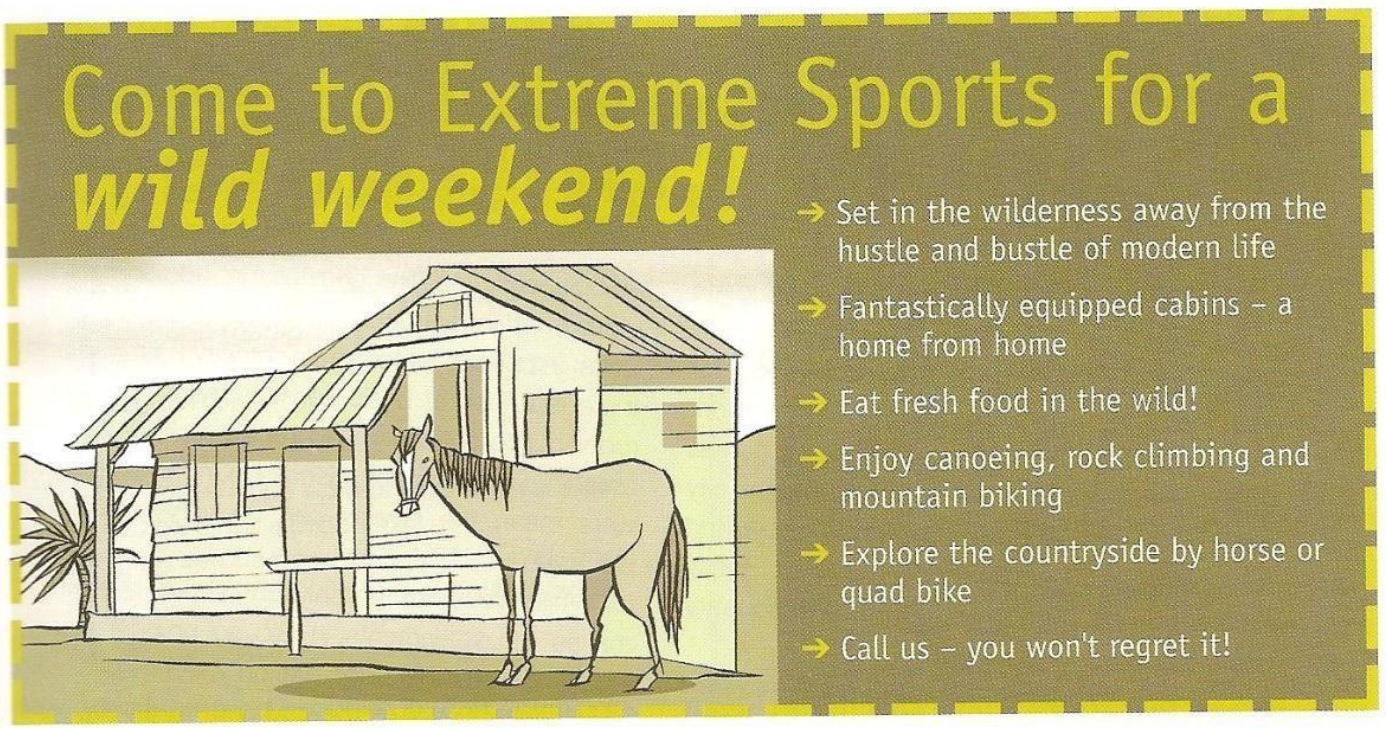

9 Use the information to write a letter of complaint.

- near motorway and airport

- planes flying over

- cabin dirty - cockroaches in the bathroom

- tinned food

- canoeing in a swimming pool

- no horses - ponies for children

- quads were broken

\section{ON AIR Can you write a formal letter of complaint?}

Make list of things that people write letters of complaint about. Choose one, and then write a letter of complaint.

¿ For help with writing letters of complaint, turn to page 113.

FINE TUNING Can you write formal and informal letters? $\Rightarrow$ Turn to page 95. 